Review

\title{
Role of heme oxygenase-1 expression by dietary phytoconstituents: A nutritional cytoprotective strategy for human diseases
}

\author{
Seung Eun Lee, Yong Seek Park* \\ Department of Microbiology, School of Medicine, Kyung Hee University, 1 Hoegi-dong, Dongdaemun-gu, Seoul 130-701 Republic of \\ Korea
}

\begin{abstract}
The present review investigates the role of the cytoprotective enzyme heme oxygenase-1 (HO-1) in human diseases and explores strategies for its clinical use. In recent years, there has been a growing evidence, for the beneficial effects of some phytoconstituents via induction of HO-1 expression, contained in commonly used spices, fruits, and herbs, in preventing various pathologic conditions, including cancer, diabetes, and cardiovascular diseases. HO-1 catalyzes the rate-limiting step in heme catabolism to generate ferrous iron, carbon monoxide, and biliverdin. HO-1 is reported to play crucial roles in cellular protection, such as anti-inflammatory, anti-proliferative and anti-apoptotic effects. These evidences indicate that HO-1 may functions as a potential therapeutic target in various human diseases. The article highlights the current status of the development of the HO-1 modulation pathway using dietary phytoconstituents.
\end{abstract}

Keywords HO-1, phytoconstituents, human diseases, pharmacological properties, molecular mechanism

\section{INTRODUCTION}

Heme oxygenase-1 (HO-1) provides an inducible defense mechanism that confers cytoprotection in response to a variety of stimuli (Ghattas et al., 2002). Induction of HO-1 expression plays an important role in the maintenance of homeostasis and stress adaptation, whereas HO-1 deficiency exhibited anemia, endothelial cell damage, tissue iron deposition, and increased inflammatory indices (Ryter and Choi, 2009; Yachie et al., 1999). Furthermore, HO-1 has been therapeutically implicated in various diseases including vascular injury, acute renal injury, hypertension and others (Morse and Choi, 2002).

In recent years, several studies have suggested that induction of HO-1 expression by dietary phytoconstituents function as a potential therapeutic target in the treatment of human disease (Chen et al., 2012b; Nakamura et al., 2011). Phytoconstituents are widely distributed in plants, and are regularly consumed in the human diet. Recent studies suggest that phytoconstituents will be useful in the prevention of various diseases, because of their antioxidant and anti-inflammatory properties (Onozuka et al., 2008; Shukla et al., 2006). In addition, various phytoconstituents induce HO-1 expression in a variety of cell types and animals; in particular, dietary phytoconstituents that have a beneficial effect in human disease may also augment HO-1 expression (Jun et al., 2012; Meng et al., 2009; Woo et al., 2012). The objective of this review is to discuss the role of HO-1 expression by dietary phytoconstituents in treatment of human diseases.

HO

HO catalyzes the first and rate-limiting step in the degradation of heme and generation of biliverdin, free iron, and carbon

\footnotetext{
*Correspondence: Yong Seek Park

E-mail: yongseek@khu.ac.kr

Received November 15, 2012; Accepted February 21, 2013;

Published February 28, 2013

doi: http://dx.doi.org/10.5667/tang.2012.0041

C2013 by Association of Humanitas Medicine

TANG / www.e-tang.org
}

monoxide (Ghattas et al., 2002). Biliverdin is subsequently converted to bilirubin by a biliverdin reductase, and iron is recycled for heme synthesis (Fig. 1). Three mammalian HO isoforms have been identified to date: $\mathrm{HO}-1, \mathrm{HO}-2$, and $\mathrm{HO}-3$ (McCoubrey et al., 1997). HO-1, a member of the stress-response protein superfamily, has a broad spectrum of inducers, including metals, cytokines, endotoxin, oxidants, and phytoconstituents (Elbirt et al., 1998; Pae et al., 2008; Sahin et al., 2010). In contrast, HO-2 is constitutively expressed and present in high levels in the brain and testes (Zabalgoitia et al., 2008) and HO-3 is not expressed in humans.

Among the various cytoprotective enzymes, HO- 1 has recently received attention as a novel enzyme with anti-inflammatory (Lee and Chau, 2002), anti-proliferative (Choi et al., 2004), and anti-apoptotic effects (Liu et al., 2003). Several studies revealed that the antioxidant and anti-inflammatory effects of HO-1 result in cytoprotective actions in the tissues, including various pathological models (Choi and Alam, 1996; Nath et al., 1992; Ohnishi et al., 2010) and induction of HO-1 has therapeutically beneficial effects in human diseases. In addition, it has been reported that deficiency of HO-1 in mice results in severe vascular damage, which is presumably mediated by a transcriptional response to injury, with specific effects on redox homeostasis, thrombosis, coagulation, and cell cycle regulation (True et al., 2007).

\section{Modulation of HO-1 expression}

Several signaling molecules and transcription factors have been found to be involved in HO-1 expression. These molecules include protein kinase $\mathrm{C}$ (PKC), phosphatidylinositol 3-kinase (PI3K), ER-localized pancreatic endoplasmic reticulum kinase (PERK), mitogen-activated protein kinases (MAPKs), nuclear factor E2-related factor 2 (Nrf2), activator protein-1 (AP-1), nuclear factor- $\kappa \mathrm{B}$ (NF- $\mathrm{BB})$, and cyclic adenosine monophosphate-response element-binding (CREB) protein (Bloom and Jaiswal, 2003; Cullinan and Diehl, 2004; Otterbein and Choi, 2000; Paine et al., 2010) (Fig. 2). The transcription factor Nrf2 plays an important role in the induction of phase II 


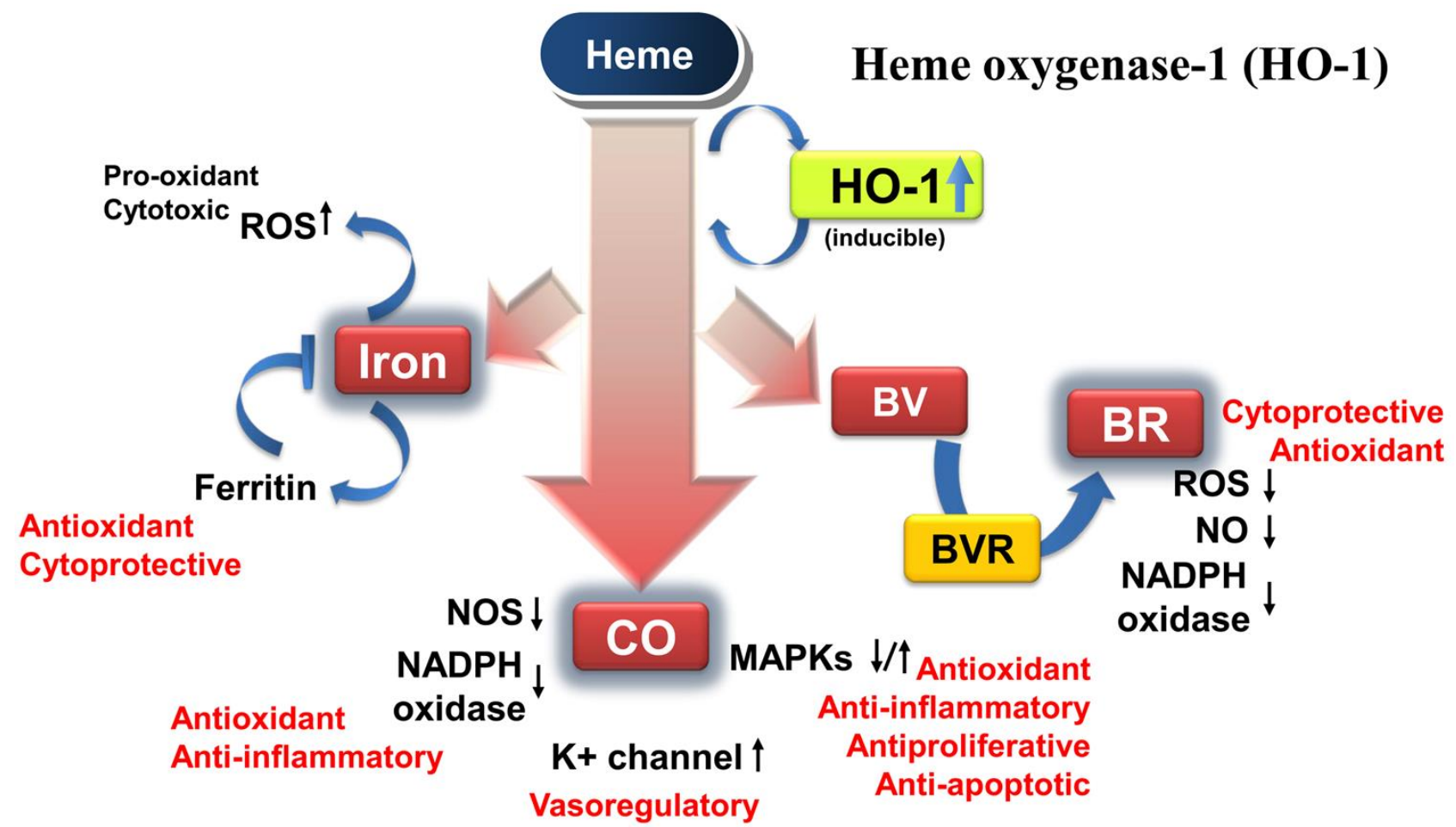

Fig. 1. Heme degradation products and their effects. HO-1 catalyze the degradation of heme to BV, with the concurrent release of Fe2+ and CO. $\mathrm{BV}$ is converted to BR by BVR. CO confers cytoprotection through restraining apoptosis, proliferation, and inflammation. BR, bilirubin; BV, biliverdin; $\mathrm{CO}$, carbon monoxide; NO, nitric oxide; NOS, nitric oxide synthase

detoxifying enzyme, including HO-1. Previous study investigated that $\mathrm{Nrf} 2$ can bind to the antioxidant responsive element (ARE) in the promoter regions of many antioxidant and phase II detoxifying genes, such as $\mathrm{NAD}(\mathrm{P}) \mathrm{H}$ : quinone oxidoreductase 1 (NQO1), glutamate cysteine ligase catalytic subunit (GCLC), and HO-1 (Randle et al., 2008). Furthermore, the activation of p38 MAPK and Nrf2 play a key role in induction of HO-1 expression in aortic endothelial cells (Chen et al., 2011) and PKC- $\delta$ and p38 MAPK play a crucial role in the activation of ARE-Nrf2 in association with HO-1 expression by curcumin in human monocytes (Rushworth et al., 2006), whereas 15-deoxy- $\Delta 12$, 14-prostaglandin J2 induces HO-1 expression via the ERK and Akt/PI3K pathway (Kim et

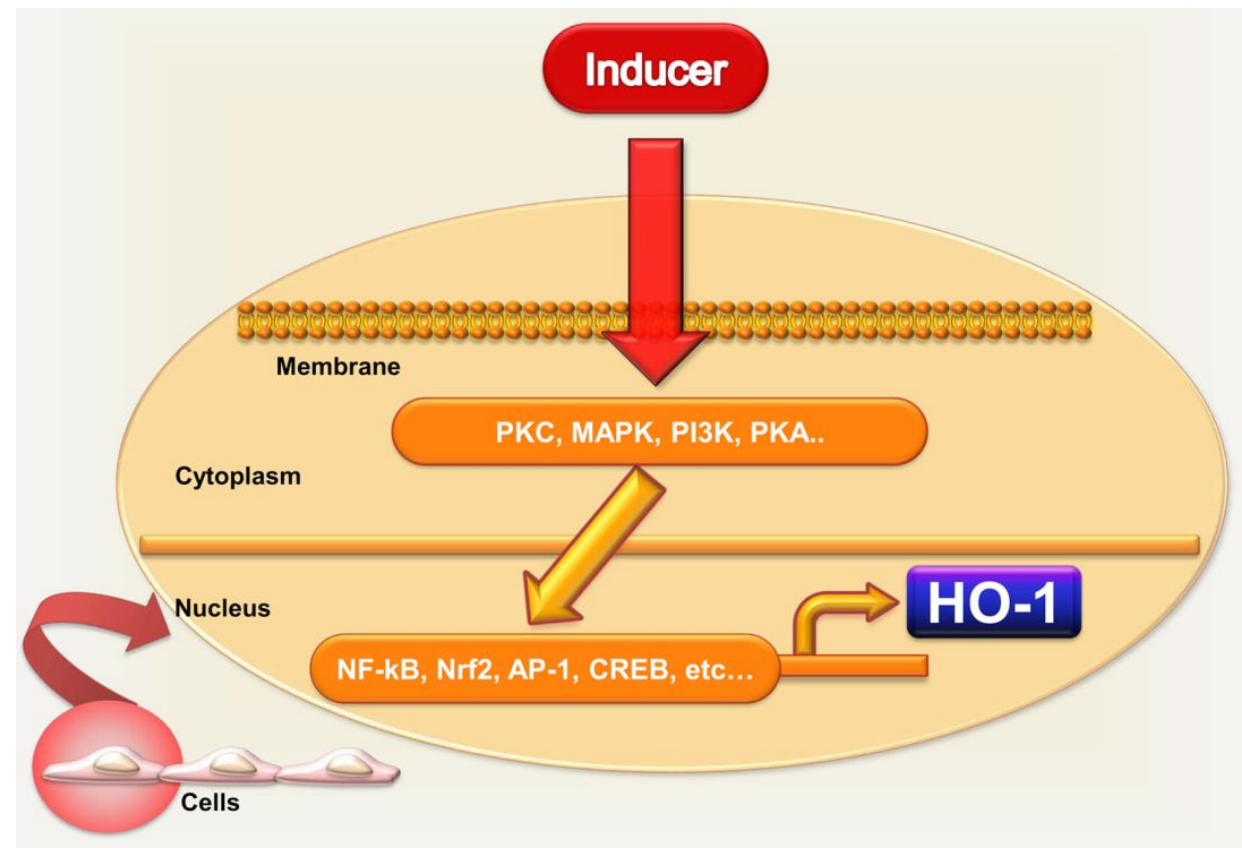

TANG / www.e-tang.org al., 2008). Our previous studies have also elucidated that fisetin, which is a flavonoid in many fruits and vegetables, has a cytoprotective effect by regulating $\mathrm{HO}-1$ expression in endothelial cells through activation of the PKC- $\delta$, p38, and Nrf2-ARE signaling pathways, whereas Danshen (Salvia miltiorrhiza) induces HO-1 expression via the PI3K/Akt, MEK1, and Nrf2 signaling pathways (Lee et al., 2012; Lee et al., 2011). There have been several excellent reviews, in effective detail, the molecular events involved in the HO-1 signaling pathway (Li et al., 2007; Paine et al., 2010; Soares et al., 2009).

Fig. 2. Modulation of HO-1 induction by transcription factors and kinases. HO-1 inducer may activate at least one or more of kinases (e.g., MAPKs, PKC, PKA, and $\mathrm{PI} 3 \mathrm{~K}$ ) and/or one of transcription factors (e.g., NF-kB, AP-1, Nrf2, CREB). Under normal conditions, the transcription factors are located in cytosol or nucleus, whereas, upon activation by stimuli, the transcription factors may translocate to the nucleus where they bind to the specific DNA sequence leading to the transcription of HO-1 gene. MAPK, mitogen-activated protein kinase; AP-1, activator protein-1; CREB, cyclic adenosine monophosphate-response element-binding protein; NF-kB, nuclear factor-kB; Nrf2, nuclear factor E2-related factor 2; PI3K, phosphatidyl inositol 3-kinase; PKA, protein kinase A; PKC, protein kinase $\mathrm{C}$. 
Table 1. Representative phytochemical inducers of HO-1

\begin{tabular}{|c|c|}
\hline Phytoconstituent & HO-1-dependent physiological effects \\
\hline EGCG & $\begin{array}{l}\text { Neuroprotection (Romeo et al., 2009; Zheng et al., 2012). Kidney protection (Kakuta et al., 2011). } \\
\text { Endothelial cell cytoprotection (Zheng et al., 2012). Cardioprotection (Dreger et al., 2008). }\end{array}$ \\
\hline Curcumin & $\begin{array}{l}\text { Neuroprotection (Scapagnini et al., 2011). Liver protection (Bao et al., 2010; Farombi et al., 2008). } \\
\text { Protection of sepsis-induced lung injury (Olszanecki et al., 2007). }\end{array}$ \\
\hline Garlic organosulfur compounds & Cancer chemoprevention (Nian et al., 2009). \\
\hline Baicalein & Neuroprotection (Choi et al., 2010). \\
\hline Quercetin & Lung protection (Hayashi et al., 2012). Liver protection (Liu et al., 2012). \\
\hline $\begin{array}{l}\text { Ampelopsin } \\
\text { (a flavonoid abundant in Rattan tea) }\end{array}$ & Neuroprotection (Kou et al., 2012). \\
\hline Ginkgo biloba extract & Liver protection (Yao et al., 2007). \\
\hline Butein & Liver protection (Yang et al., 2011). \\
\hline Anthocyanin & Neuroprotection (Kim et al., 2012). Liver protection (Hwang et al., 2011). \\
\hline Luteolin & Kidney protection (Wang et al., 2011). Neuroprotection (Lin et al., 2010). \\
\hline $\begin{array}{l}\text { Berberine (the major constituents of } \\
\text { chinese herb Rhizoma coptidis) }\end{array}$ & Neuroprotection (Chen et al., 2012a). \\
\hline Sulforaphane & Neuroprotection (Hong et al., 2010). \\
\hline Salvianolic acid B & Vasoprotective action (Joe et al., 2012). \\
\hline Rosmarinic acid & Neuroprotection (Lee et al., 2008). \\
\hline
\end{tabular}

\section{Effect of HO-1 expression by dietary phytoconstituents}

HO-1 exerts multifunctional roles in the development of various diseases. The HO system could attenuate/block the progression of diseases via their antioxidant, anti-inflammatory, and anti-proliferative effects. Also, HO-1 cooperates with its downstream products, $\mathrm{CO}$ and bilirubin to exert diverse cellular protective effects and serve as potential therapeutic targets.

Dietary phytoconstituents present in a multitude of dietary sources have been reported to possess potent antioxidant and anti-inflammatory activities as well as the ability to modulate a variety of signaling mechanisms. Various phytoconstituents have been identified and studied using modern scientific approaches and the results exhibited the potential of phytoconstituents in the field of pharmacology (Tapsell et al., 2006; Triggiani et al., 2006). Current study into approaches to use of HO-1 in clinical apply has become progressively focused on the use of phytochemical inducers (phytoconstituents) of the enzyme. Several phytoconstituents are known inducers of HO- 1 and therefore represent attractive candidates for use in healthcare.

A possible general mechanism of cytoprotective activity of phytoconstituents, correlated with their ability to regulates protective inducible genes, is their involvement in the cellular stress response (Mattson et al., 2007). Consumption of phytoconstituents from varied sources has been shown to possess the ability to cause activation of the HO-1 signaling mechanisms. Dietary phytoconstituents, such as epigallocatechin-3-gallate (EGCG) obtained from tea leaves, fisetin from strawberries, resveratrol from grapes, carnosic acid (CA) from the herb rosemary as well as tetramethylpyrazine (TMP) from chinese medicinal herb Ligusticum wallichii Franchat have been identified to possess HO-1 modulatory properties (Chen et al., 2006; Kakuta et al., 2011; Lee et al., 2011; Mimura et al., 2011; Ren et al., 2011). In Table 1, we have presented numerous studies which have investigated the cytoprotective effect of a number of phytoconstituents, regarding their effects on the HO-1 regulatory systems.

\section{HO-1 and cardiovascular health}

It was recently revealed that $\mathrm{HO}-1$ is a potential therapeutic target in the treatment of vascular disease (Durante, 2010). HO-1, which is highly expressed in tissues such as the heart and blood vessels, protects against vascular diseases, and has a cytoprotective effect in the circulation. Induction of HO-1 expression in the endothelial cells reduces platelet aggregation and smooth muscle cell proliferation (Zhang et al., 2002; Sato et al., 2001), whereas HO-1 deficiency in humans shows evidence of oxidative injury and severe endothelial damage (Yachie et al., 1999). These results indicate that HO-1 plays an important role in the vascular system as a potent protector against cardiovascular disease. Our previous studies have suggested that HO-1 expression induced by flavonoids such as fisetin protects against oxidative stress-induced cell death in endothelial cells and Danshen may also have cytoprotective activity through the induction of HO-1 expression (Lee et al., 2012; Lee et al., 2011). These data supports the potential therapeutic mechanism of Danshen and fisetin in protecting against oxidative stress-related diseases such as vascular disease. In other studies, Meng et al. (2009) showed that HO-1 activity was proposed as a mechanism to account for the protection of vascular responses by puerarin and 2-methoxycinnamaldehyde (2-MCA), one of active ingredients of Cinnamomum cassia, has been reported to protect against myocardial I/R-injury due to antioxidant and anti-inflammatory action possibly by HO-1 induction (Hwa et al., 2012). These findings strongly suggest that induction of $\mathrm{HO}-1$ expression by dietary phytoconstituents serve as key modulators for vascular inflammation, endothelial cells (EC) function, and vascular smooth muscle cells (VSMC) proliferation, which are pathogenic factors for human cardiovascular diseases.

\section{HO-1 and hepatic health}

Increasing evidence supports that $\mathrm{HO}-1$ induction represents an adaptive response or enhanced resistance against various oxidative stresses. It has been reported that pharmacological induction of HO-1 may have strong therapeutic potential in hypoxia or inflammation that induces severe liver damage (Tuzuner et al., 2004). In recent, several studies also provides biological evidence that supports the use of phytoconstituents in the treatment of liver disorders via induction of HO-1, including Ginkgo biloba extract (Yao et al., 2007), anthocyanin from purple sweet potato (Hwang et al., 2011) and curcumin from the curry spice turmeric (Bao et al., 2010; Farombi et al., 2008).

\section{HO-1 and pulmonary disease}

The identification of HO-1 as a vital negative modulator in inflammation has provoked intense interest in exploring the role played by HO-1 in acute lung injury (Morse and Choi, 2002). The outcome of recent studies to identify the mechanisms of oxidative damage in lung disease have shown HO-1 to be a critical signaling molecule leading to protection 
of lung tissue, the disruption of which may result in disease. A recent study suggested that quercetin may lead to new therapeutic strategies for antifibrotic therapy in the treatment of respiratory diseases through induction of HO-1 (Nakamura et al., 2011). In other studies, dietary phytoconstituents (such as curcumin) also confers protection against oxidative stress-related pulmonary disease and its therapeutic effects depend on transcriptional upregulation of HO-1 (Olszanecki et al., 2007; Lee et al., 2010).

\section{HO-1 and neuroprotection}

Oxidative stress plays a role in the onset and progression of a wide range of neuronal diseases that affect the tissue of the central nervous system, which consists of the brain and spinal cord plus the peripheral nervous system (Browne and Beal, 1994). Ongoing studies by several investigators have revealed potential for the use of $\mathrm{HO}-1$ as an anti-ischemic agent. Furthermore, induction of HO-1 expression using dietary phytoconstituents has also shown promise as a strategy for management of neurological damage. Romeo et al. (2009) demonstrated that pharmacological activation of HO-1 by EGCG efficiently protects neurons from oxidative stress and should be evaluated as a new therapeutic approach for treatment and prevention of diseases that correlate with oxidative damage, such as diabetic neuropathy. The neuroprotective effect of ampelopsin, a phytoconstituent abundant in Rattan tea (Ampelopsis grossedentata), was also showed to be related to attenuation of reactive oxygen species formation, inhibition of poly (ADP-ribose) polymerase and caspase- 3 and inhibition of p38 MAPK phosphorylation, as well as up-regulation of HO-1 expression, suggesting that ampelopsin is a promising candidate for the treatment of neurodegenerative diseases (Kou et al., 2012).

\section{HO-1 and renoprotective effect}

In kidneys, the protective properties of $\mathrm{HO}-1$ have been revealed in a variety of renal injury models including ischemia-reperfusion and cisplatin nephrotoxicity (Salom et al., 2007; Shiraishi et al., 2000; Tracz et al., 2007). Induction of HO-1 protects against oxidative stress, endothelial cell loss, and vascular dysfunction that occur in streptozotocin-induced diabetes, indicating that, in the diabetic milieu, upregulation of HO-1 can confer beneficial effects in the kidney (Abraham et al., 2004; Quan et al., 2004; Turkseven et al., 2005). Ongoing investigations into strategies for use of induction of HO-1 by dietary phytoconstituents in inhibiting oxidative damage to renal tissue have yielded some very interesting results. Recent report suggested that augmentation of HO-1 may exert protective effect of EGCG in rat kidneys from I/R injury, which was attributed to reduced macrophage infiltration via monocyte chemoattractant protein-1 down-regulation, and decreased renal fibrosis via transforming growth factor- $\beta 1$ down-regulation (Kakuta et al., 2011). In the meantime, other groups have reported renoprotective effect of luteolin may be related to increasing HO-1 expression and elevating antioxidant in diabetic nephropathy (Wang et al., 2011).

\section{CONCLUSION}

The last decade has seen an increase in the interest of phytoconstituents. This review has shown that dietary phytoconstituents can modulate HO-1 signaling pathway and thus has potential therapeutic value against various chronic diseases including cardiovascular diseases, pulmonary diseases, renal diseases and neurodegenerative diseases. Thus, we hypothesise that HO-1 expression by dietary phytoconstituents may provide new insights for treatment of various human disease.

\section{ACKNOWLEDGEMENTS}

This study was supported by a grant of the Korean Health Technology R\&D Project, ministry of Health \& Welfare, Republic of Korea (A111834).

\section{CONFLICT OF INTEREST}

The authors have no conflicting financial interests.

\section{REFERENCES}

Abraham NG, Rezzani R, Rodella L, Kruger A, Taller D, Li Volti G, Goodman AI, Kappas A. Overexpression of human heme oxygenase-1 attenuates endothelial cell sloughing in experimental diabetes. Am J Physiol Heart Circ Physiol. 2004;287:H2468-H2477.

Bao W, Li K, Rong S, Yao P, Hao L, Ying C, Zhang X, Nussler A, Liu L. Curcumin alleviates ethanol-induced hepatocytes oxidative damage involving heme oxygenase-1 induction. J Ethnopharmacol. 2010;128:549-553.

Bloom DA, Jaiswal AK. Phosphorylation of Nrf2 at Ser40 by protein kinase $\mathrm{C}$ in response to antioxidants leads to the release of Nrf2 from INrf2, but is not required for Nrf2 stabilization/accumulation in the nucleus and transcriptional activation of antioxidant response element-mediated NAD(P)H:quinone oxidoreductase-1 gene expression. J Biol Chem. 2003;278:44675-44682.

Browne SE, Beal MF. Oxidative damage and mitochondrial dysfunction in neurodegenerative diseases. Biochem Soc Trans. 1994;22:1002-1006.

Chen JH, Huang SM, Tan TW, Lin HY, Chen PY, Yeh WL, Chou SC, Tsai CF, Wei IH, Lu DY. Berberine induces heme oxygenase-1 up-regulation through phosphatidylinositol 3-kinase/AKT and NF-E2-related factor-2 signaling pathway in astrocytes. Int Immunopharmacol. 2012a;12:94-100.

Chen JS, Huang PH, Wang CH, Lin FY, Tsai HY, Wu TC, Lin SJ, Chen JW. Nrf- 2 mediated heme oxygenase-1 expression, an antioxidant-independent mechanism, contributes to anti-atherogenesis and vascular protective effects of Ginkgo biloba extract. Atherosclerosis. 2011;214:301-309.

Chen S, Ding Y, Tao W, Zhang W, Liang T, Liu C. Naringenin inhibits TNF-alpha induced VSMC proliferation and migration via induction of HO-1. Food Chem Toxicol. 2012b;50:3025-3031.

Chen SY, Hsiao G, Hwang HR, Cheng PY, Lee YM. Tetramethylpyrazine induces heme oxygenase- 1 exprßession and attenuates myocardial ischemia/reperfusion injury in rats. $\mathbf{J}$ Biomed Sci. 2006;13:731-740.

Choi AM, Alam J. Heme oxygenase-1: function, regulation, and implication of a novel stress-inducible protein in oxidant-induced lung injury. Am J Respir Cell Mol Biol. 


\section{6;15:9-19.}

Choi BM, Kim YM, Jeong YR, Pae HO, Song CE, Park JE, Ahn YK, Chung HT. Induction of heme oxygenase-1 is involved in anti-proliferative effects of paclitaxel on rat vascular smooth muscle cells. Biochem Biophys Res Commun. 2004;321:132-137.

Choi JH, Choi AY, Yoon H, Choe W, Yoon KS, Ha J, Yeo EJ, Kang I. Baicalein protects HT22 murine hippocampal neuronal cells against endoplasmic reticulum stress-induced apoptosis through inhibition of reactive oxygen species production and CHOP induction. Exp Mol Med. 2010;42:811-822.

Cullinan SB, Diehl JA. PERK-dependent activation of Nrf2 contributes to redox homeostasis and cell survival following endoplasmic reticulum stress. J Biol Chem. 2004;279:20108-20117.

Dreger H, Lorenz M, Kehrer A, Baumann G, Stangl K, Stangl V. Characteristics of catechin- and theaflavin-mediated cardioprotection. Exp Biol Med (Maywood). 2008;233:427-433.

Durante W. Targeting heme oxygenase-1 in vascular disease. Curr Drug Targets. 2010;11:1504-1516.

Elbirt KK, Whitmarsh AJ, Davis RJ, Bonkovsky HL. Mechanism of sodium arsenite-mediated induction of heme oxygenase-1 in hepatoma cells. Role of mitogen-activated protein kinases. J Biol Chem. 1998;273:8922-8931.

Farombi EO, Shrotriya S, Na HK, Kim SH, Surh YJ. Curcumin attenuates dimethylnitrosamine-induced liver injury in rats through Nrf2-mediated induction of heme oxygenase-1. Food Chem Toxicol. 2008;46:1279-1287.

Ghattas MH, Chuang LT, Kappas A, Abraham NG. Protective effect of HO-1 against oxidative stress in human hepatoma cell line (HepG2) is independent of telomerase enzyme activity. Int J Biochem Cell Biol. 2002;34:1619-1628.

Hayashi Y, Matsushima M, Nakamura T, Shibasaki M, Hashimoto N, Imaizumi K, Shimokata K, Hasegawa Y, Kawabe T. Quercetin protects against pulmonary oxidant stress via heme oxygenase-1 induction in lung epithelial cells. Biochem Biophys Res Commun. 2012;417:169-174.

Hong YA, Yan W, Chen S, Sun CR, Zhang JM. The role of Nrf2 signaling in the regulation of antioxidants and detoxifying enzymes after traumatic brain injury in rats and mice. Acta Pharmacol Sin. 2010;31:1421-1430.

Hwa JS, Jin YC, Lee YS, Ko YS, Kim YM, Shi LY, Kim HJ, Lee JH, Ngoc TM, Bae KH, Kim YS, Chang KC. 2-Methoxycinnamaldehyde from Cinnamomum cassia reduces rat myocardial ischemia and reperfusion injury in vivo due to HO-1 induction. J Ethnopharmacol. 2012;139:605-615.

Hwang YP, Choi JH, Choi JM, Chung YC, Jeong HG. Protective mechanisms of anthocyanins from purple sweet potato against tert-butyl hydroperoxide-induced hepatotoxicity. Food Chem Toxicol. 2011;49:2081-2089.

Joe Y, Zheng M, Kim HJ, Kim S, Uddin MJ, Park C, Ryu do G, Kang SS., Ryoo S, Ryter SW, Chang KC, Chung HT. Salvianolic acid B exerts vasoprotective effects through the modulation of heme oxygenase-1 and arginase activities. J Pharmacol Exp Ther. 2012;341:850-858.

Jun MS, Kim HS, Kim YM, Kim HJ, Park EJ, Lee JH, Lee KR, Kim YS, Chang KC. Ethanol extract of Prunella vulgaris var. lilacina inhibits HMGB1 release by induction of heme oxygenase-1 in LPS-activated RAW 264.7 cells and CLP-induced septic mice. Phytother Res. 2012;26:605-612.

Kakuta Y, Okumi M, Isaka Y, Tsutahara K, Abe T, Yazawa K, Ichimaru N, Matsumura K, Hyon SH, Takahara S, Nonomura $\mathrm{N}$. Epigallocatechin-3-gallate protects kidneys from ischemia reperfusion injury by HO-1 upregulation and inhibition of macrophage infiltration. Transpl Int. 2011;24:514-522.

Kim JW, Li MH, Jang JH, Na HK, Song NY, Lee C, Johnson JA, Surh YJ. 15-Deoxy-Delta12,14-prostaglandin J2 rescues $\mathrm{PC} 12$ cells from H2O2-induced apoptosis through Nrf2-mediated upregulation of heme oxygenase-1: Potential roles of Akt and ERK1/2. Biochem Pharmacol. 2008;76:1577-1589.

Kim SM, Chung MJ, Ha TJ, Choi HN, Jang SJ, Kim SO, Chun MH, Do SI, Choo YK, Park YI. Neuroprotective effects of black soybean anthocyanins via inactivation of ASK1-JNK/p38 pathways and mobilization of cellular sialic acids. Life Sci. 2012;90:874-882.

Kou XJ, Shen KY, An YH, Qi SM, Dai WX, Yin ZM. Ampelopsin inhibits $\mathrm{H}_{2} \mathrm{O}_{2}$-induced apoptosis by ERK and Akt signaling pathways and up-regulation of heme oxygenase-1. Phytother Res. 2012;26:988-994.

Lee HJ, Cho HS, Park E, Kim S, Lee SY, Kim CS, Kim DK, Kim SJ, Chun HS. Rosmarinic acid protects human dopaminergic neuronal cells against hydrogen peroxide-induced apoptosis. Toxicology. 2008;250:109-115.

Lee JC, Kinniry PA, Arguiri E, Serota M, Kanterakis S, Chatterjee S, Solomides CC, Javvadi P, Koumenis C, Cengel KA, Christofidou-Solomidou M. Dietary curcumin increases antioxidant defenses in lung, ameliorates radiation-induced pulmonary fibrosis, and improves survival in mice. Radiat Res. 2010;173:590-601.

Lee SE, Jeong SI, Yang H, Jeong SH, Jang YP, Park CS, Kim J Park YS. Extract of Salvia miltiorrhiza (Danshen) induces Nrf2-mediated heme oxygenase-1 expression as a cytoprotective action in RAW 264.7 macrophages. J Ethnopharmacol. 2012;139:541-548.

Lee SE, Jeong SI, Yang H, Park CS, Jin YH, Park YS. Fisetin induces Nrf2-mediated HO-1 expression through PKC-delta and p38 in human umbilical vein endothelial cells. J Cell Biochem. 2011;112:2352-2360.

Lee TS, Chau LY. Heme oxygenase-1 mediates the anti-inflammatory effect of interleukin-10 in mice. Nat Med. 2002;8:240-246.

Li C, Hossieny P, Wu BJ, Qawasmeh A, Beck K, Stocker R. Pharmacologic induction of heme oxygenase-1. Antioxid Redox Signal. 2007;9:2227-2239.

Lin CW, Wu MJ, Liu, I YC, Su JD, Yen JH. Neurotrophic and cytoprotective action of luteolin in $\mathrm{PC} 12$ cells through ERK-dependent induction of Nrf2-driven HO-1 expression. J 
Agric Food Chem. 2010;58:4477-4486.

Liu H, Nowak R, Chao W, Bloch KD. Nerve growth factor induces anti-apoptotic heme oxygenase-1 in rat pheochromocytoma PC12 cells. J Neurochem. 2003;86:1553-1563.

Liu S, Hou W, Yao P, Li N, Zhang B, Hao L, Nüssler AK, Liu L. Heme oxygenase-1 mediates the protective role of quercetin against ethanol-induced rat hepatocytes oxidative damage. Toxicol In Vitro. 2012;26:74-80.

Mattson MP, Son TG, Camandola S. Viewpoint: mechanisms of action and therapeutic potential of neurohormetic phytochemicals. Dose Response. 2007;5:174-186.

McCoubrey WK, Huang TJ, Maines MD. Isolation and characterization of a cDNA from the rat brain that encodes hemoprotein heme oxygenase-3. Eur J Biochem. 1997;247:725-732.

Meng XH, Ni C, Zhu L, Shen YL, Wang LL, Chen YY. Puerarin protects against high glucose-induced acute vascular dysfunction: role of heme oxygenase-1 in rat thoracic aorta. Vascul Pharmacol. 2009;50:110-115.

Mimura J, Kosaka K, Maruyama A, Satoh T, Harada N, Yoshida H, Satoh K, Yamamoto M, Itoh K. Nrf2 regulates NGF mRNA induction by carnosic acid in T98G glioblastoma cells and normal human astrocytes. J Biochem. 2011;150:209-217.

Morse D, Choi AM. Heme oxygenase-1: The "emerging molecule" has arrived. Am J Respir Cell Mol Biol. 2002;27:8-16.

Nakamura T, Matsushima M, Hayashi Y, Shibasaki M, Imaizumi K, Hashimoto N, Shimokata K, Hasegawa Y, Kawabe T. Attenuation of transforming growth factor-beta-stimulated collagen production in fibroblasts by quercetin-induced heme oxygenase-1. Am J Respir Cell Mol Biol. 2011;44:614-620.

Nath KA, Balla G, Vercellotti GM, Balla J, Jacob HS, Levitt MD, Rosenberg ME. Induction of heme oxygenase is a rapid, protective response in rhabdomyolysis in the rat. J Clin Invest. 1992;90:267-270.

Nian H, Delage B, Ho E, Dashwood RH. Modulation of histone deacetylase activity by dietary isothiocyanates and allyl sulfides: Studies with sulforaphane and garlic organosulfur compounds. Environ Mol Mutagen. 2009;50:213-221.

Ohnishi M, Katsuki H, Unemura K, Izumi Y, Kume T, Takada-Takatori Y, Akaike A. Heme oxygenase-1 contributes to pathology associated with thrombin-induced striatal and cortical injury in organotypic slice culture. Brain Res. 2010;1347:170-178.

Olszanecki R, Gebska A, Korbut R. The role of haem oxygenase- 1 in the decrease of endothelial intercellular adhesion molecule-1 expression by curcumin. Basic Clin Pharmacol Toxicol. 2007;101:411-415.

Onozuka H, Nakajima A, Matsuzaki K, Shin RW, Ogino K, Saigusa D, Tetsu N, Yokosuka A, Sashida Y, Mimaki Y, Yamakuni T, Ohizumi Y. Nobiletin, a citrus flavonoid, improves memory impairment and Abeta pathology in a transgenic mouse model of Alzheimer's disease. J Pharmacol Exp Ther. 2008;326:739-744.

Otterbein LE, Choi AM. Heme oxygenase: colors of defense against cellular stress. Am J Physiol Lung Cell Mol Physiol. 2000;279:L1029-L1037.

Pae HO, Lee YC, Chung HT. Heme oxygenase-1 and carbon monoxide: emerging therapeutic targets in inflammation and allergy. Recent Pat Inflamm Allergy Drug Discov. 2008;2:159-165.

Paine A, Eiz-Vesper B, Blasczyk R, Immenschuh S. Signaling to heme oxygenase-1 and its anti-inflammatory therapeutic potential. Biochem Pharmacol. 2010;80:1895-1903.

Quan S, Kaminski PM, Yang L, Morita T, Inaba M, Ikehara S, Goodman AI, Wolin MS, Abraham NG. Heme oxygenase-1 prevents superoxide anion-associated endothelial cell sloughing in diabetic rats. Biochem Biophys Res Commun. 2004;315:509-516.

Randle LE, Goldring CE, Benson CA, Metcalfe PN, Kitteringham NR, Park BK, Williams DP. Investigation of the effect of a panel of model hepatotoxins on the Nrf2-Keap1 defence response pathway in CD-1 mice. Toxicology. 2008;243:249-260

Ren J, Fan C, Chen N, Huang J, Yang Q. Resveratrol pretreatment attenuates cerebral ischemic injury by upregulating expression of transcription factor Nrf2 and HO-1 in rats. Neurochem Res. 2011;36:2352-2362.

Romeo L, Intrieri M, D'Agata V, Mangano NG, Oriani G, Ontario ML, Scapagnini G. The major green tea polyphenol, (-)-epigallocatechin-3-gallate, induces heme oxygenase in rat neurons and acts as an effective neuroprotective agent against oxidative stress. J Am Coll Nutr. 2009;28:492S-499S.

Rushworth SA, Ogborne RM, Charalambos CA, O'Connell MA Role of protein kinase $\mathrm{C}$ delta in curcumin-induced antioxidant response element-mediated gene expression in human monocytes. Biochem Biophys Res Commun. 2006;341:1007-1016.

Ryter SW, Choi AM. Heme oxygenase-1/carbon monoxide: from metabolism to molecular therapy. Am J Respir Cell Mol Biol. 2009;41:251-260.

Sahin K, Tuzcu M, Sahin N, Ali S, Kucuk O. Nrf2/HO-1 signaling pathway may be the prime target for chemoprevention of cisplatin-induced nephrotoxicity by lycopene. Food Chem Toxicol. 2010;48:2670-2674.

Salom MG, Ceron SN, Rodriguez F, Lopez B, Hernandez I, Martinez JG, Losa AM, Fenoy FJ. Heme oxygenase-1 induction improves ischemic renal failure: role of nitric oxide and peroxynitrite. Am J Physiol Heart Circ Physiol. 2007;293:H3542- H3549.

Sato K, Balla J, Otterbein L, Smith RN, Brouard S, Lin Y, Csizmadia E, Sevigny J, Robson SC, Vercellotti G, Choi AM, Bach FH, Soares MP. Carbon monoxide generated by heme oxygenase-1 suppresses the rejection of mouse-to-rat cardiac transplants. J Immunol. 2001;166:4185-4194. 
Scapagnini G, Caruso C, Calabrese V. Therapeutic potential of dietary polyphenols against brain ageing and neurodegenerative disorders. Adv Exp Med Biol. 2010;698:27-35.

Shiraishi F, Curtis LM, Truong L, Poss K, Visner GA, Madsen K, Nick HS, Agarwal A. Heme oxygenase-1 gene ablation or expression modulates cisplatin-induced renal tubular apoptosis. Am J Physiol Renal Physiol. 2000;278:F726-F736.

Shukla R, Barve V, Padhye S, Bhonde R. Reduction of oxidative stress induced vanadium toxicity by complexing with a flavonoid, quercetin: a pragmatic therapeutic approach for diabetes. Biometals. 2006;19:685-693.

Soares MP, Marguti I, Cunha A, Larsen R. Immunoregulatory effects of HO-1: how does it work? Curr Opin Pharmacol. 2009;9:482-489.

Tapsell LC, Hemphill I, Cobiac L, Patch CS, Sullivan DR, Fenech M, Roodenrys S, Keogh JB, Clifton PM, Williams PG, Fazio VA, Inge KE. Health benefits of herbs and spices: the past, the present, the future. Med J Aust. 2006;185:S4-S24.

Tracz MJ, Juncos JP, Croatt AJ, Ackerman AW, Grande JP, Knutson KL, Kane GC, Terzic A, Griffin MD, Nath KA. Deficiency of heme oxygenase-1 impairs renal hemodynamics and exaggerates systemic inflammatory responses to renal ischemia. Kidney Int. 2007;72:1073-1080.

Triggiani V, Resta F, Guastamacchia E, Sabba C, Licchelli B, Ghiyasaldin S, Tafaro E. Role of antioxidants, essential fatty acids, carnitine, vitamins, phytochemicals and trace elements in the treatment of diabetes mellitus and its chronic complications. Endocr Metab Immune Disord Drug Targets. 2006;6:77-93.

True AL, Olive M, Boehm M, San H, Westrick RJ, Raghavachari N, Xu X, Lynn EG, Sack MN, Munson PJ, Gladwin MT, Nabel EG. Heme oxygenase-1 deficiency accelerates formation of arterial thrombosis through oxidative damage to the endothelium, which is rescued by inhaled carbon monoxide. Circ Res. 2007;101:893-901.

Turkseven S, Kruger A, Mingone CJ, Kaminski P, Inaba M, Rodella LF, Ikehara S, Wolin MS, Abraham NG. Antioxidant mechanism of heme oxygenase- 1 involves an increase in superoxide dismutase and catalase in experimental diabetes. Am J Physiol Heart Circ Physiol. 2005;289:H701-H707.
Tüzüner E, Liu LG, Shimada M, Yilmaz E, Glanemann M, Settmacher U, Langrehr JM, Jonas S, Neuhaus P, Nussler AK. Heme oxygenase-1 protects human hepatocytes in vitro against warm and cold hypoxia. J Hepatol. 2004;41:764-772.

Wang GG, Lu XH, Li W, Zhao X, Zhang C. Protective effects of luteolin on diabetic nephropathy in STZ-induced diabetic rats. Evid Based Complement Alternat Med. 2011;2011:323171.

Woo JM, Shin DY, Lee SJ, Joe Y, Zheng M, Yim JH, Callaway Z, Chung HT. Curcumin protects retinal pigment epithelial cells against oxidative stress via induction of heme oxygenase-1 expression and reduction of reactive oxygen. Mol Vis. 2012;18:901-908.

Yachie A, Niida Y, Wada T, Igarashi N, Kaneda H, Toma T, Ohta K, Kasahara Y, Koizumi S. Oxidative stress causes enhanced endothelial cell injury in human heme oxygenase-1 deficiency. J Clin Invest. 1999;103:129-135.

Yang YC, Lii CK, Lin AH, Yeh YW, Yao HT, Li CC, Liu KL, Chen HW. Induction of glutathione synthesis and heme oxygenase 1 by the flavonoids butein and phloretin is mediated through the ERK/Nrf2 pathway and protects against oxidative stress. Free Radic Biol Med. 2011;51:2073-2081.

Yao P, Li K, Song F, Zhou S, Sun X, Zhang X, Nüssler AK, Liu L. Heme oxygenase-1 upregulated by Ginkgo biloba extract: potential protection against ethanol-induced oxidative liver damage. Food Chem Toxicol. 2007;45:1333-1342.

Zabalgoitia M, Colston JT, Reddy SV, Holt JW, Regan RF, Stec DE, Rimoldi JM, Valente AJ, Chandrasekar B. Carbon monoxide donors or heme oxygenase-1 (HO-1) overexpression blocks interleukin-18-mediated NF-kappaB-PTEN-dependent human cardiac endothelial cell death. Free Radic Biol Med. 2008;44:284-298.

Zhang M, Zhang BH, Chen L, An W. Overexpression of heme oxygenase-1 protects smooth muscle cells against oxidative injury and inhibits cell proliferation. Cell Res. 2002;12:123-132.

Zheng Y, Morris A, Sunkara M, Layne J, Toborek M, Hennig B. Epigallocatechin-gallate stimulates NF-E2-related factor and heme oxygenase-1 via caveolin-1 displacement. J Nutr Biochem. 2012;23:163-168. 